\title{
Alguns bestiários na literatura brasileira contemporânea
}

Eduardo Jorge de Oliveira e Maria Elisa Rodrigues Moreira ${ }^{1}$

RESUMO: Este texto propõe uma leitura da produção literária brasileira contemporânea de escritores que mergulham no universo imaginário dos bestiários e compõe uma espécie de zooliteratura, como Claudio Daniel, Wilson Bueno, Ronald Polito e Nuno Ramos, entre outros, tendo como ponto de partida os bestiários medievais e os bestiários de autores como Jorge Luis Borges e Julio Cortázar, fundamentais às obras dos referidos autores contemporâneos.

ABSTRACT: This paper proposes a reading of the contemporary Brazilian literary production of the authors like Claudio Daniel, Wilson Bueno, Ronald Polito, and Nuno Ramos, amongst others, that go into the imaginary universe of the bestiaries in order to compose a sort of zoo-literature, by using as a starting point the medieval bestiaries of authors like Jorge Luis Borges and Julio Cortázar, and their fundamental pieces to the work of the referred contemporary authors.

PALAVRAS-CHAVE: Bestiários medievais; Literatura brasileira contemporânea; Zooliteratura.

KEYWORDS: Medieval bestiaries; Contemporary Brazilian literature; Zoo-literature.

Este texto propõe uma leitura da produção literária brasileira contemporânea de escritores que mergulham no universo imaginário dos bestiários e compõem uma espécie de zooliteratura, em especial de algumas obras de Claudio Daniel, Wilson Bueno, Ronald Polito e Nuno Ramos. O ponto de partida para se pensar essa produção contemporânea são os bestiários medievais e sua releitura feita por autores como Julio Cortázar e Jorge Luis Borges, fundamentais às obras dos referidos autores brasileiros sobre os quais nos dispusemos a refletir.

\footnotetext{
${ }^{1}$ Mestrando e doutoranda do Programa de Pós- Graduação da UFMG.
} 
É possivel associar as origens do bestiário ao período clássico greco-latino e a autores como Plínio o Velho e sua História natural, embora o modelo por excelência dos bestiários medievais tenha sido o Physiologus, obra grega de autoria incerta, escrita em Alexandria, entre os séculos I e III, cujo original nunca foi encontrado. Entretanto, devido à sua popularidade, foram produzidas traduções para diversas línguas. Possivelmente a primeira tradução para o latim apareceu já no século V (VARANDAS, 2006; MACIEL, 2008). Ao longo dos séculos, este modelo foi se transformando e incorporando características diversas, em especial do universo cristão, tendo sido fundamental a interferência sobre o mesmo das Etimologias de Santo Isidoro de Sevilha que, a partir do século XII, passam a reorganizar a estrutura do Physiologus: "a divisão dos capítulos, a importância atribuída à etimologia dos nomes dos animais, o tipo de descrição da criatura e sua respectiva moralização baseiam-se em Isidoro" (VARANDAS, 2006, p. 6).

Conforme Maciel (2008), entretanto, é apenas entre os séculos XII e XIV que o bestiário vai se afirmar enquanto gênero, como um livro que aborda, classifica e cataloga animais reais ou fabulosos. Tornando-se assim bastante popular ao longo da Idade Média, o bestiário podia apresentar-se em prosa ou em verso, mas caracterizava-se principalmente pela integração entre imagem e texto verbal através da constante presença das iluminuras e por possuir, na maior parte dos casos, um caráter moral e uma intenção pedagógica. ${ }^{2}$ De acordo com Angélica Varandas, a organização do bestiário se dá em torno de pequenas narrativas descritivas das diversas espécies animais, cuja principal marca é o caráter moral e didático, responsável pela forma de composição desses livros: cada narrativa é composta por duas partes distintas, uma parte descritiva da espécie em questão (que, lembramos, pode ser existente ou não) e sua interpretação simbólico-alegórica, ou moralização. Os animais passam a funcionar, assim, como "símbolos de

\footnotetext{
2 Ainda que se conheçam casos de bestiários que se caracterizassem pela sátira e pelo erotismo, eles eram a minoria no escopo dos bestiários medievais.
} 
vícios ou virtudes e fonte de ensinamentos religiosos e morais" (VARANDAS, 2006, p. 1).

Por apresentar uma visão "poética do mundo", marcada pela mistura de ciência, erudição e imaginação que caracterizava a composição do saber da época, os bestiários foram fortes influências para o desenvolvimento da alegoria e do simbolismo na literatura e nas artes, como afirmou Virginia Naughton:

O Bestiário constitui um dos tópicos alegóricos fundamentais da Idade Média e, a partir de sua leitura, é possível reconstruir as relações que o homem medievo mantinha com a natureza e, ao mesmo tempo nos permite localizar sua posição no esquema geral das coisas criadas. Junto a esta zoologia simbólica, deve situar-se também aquela medicina imaginária, cuja base de credibilidade e ampla aceitação surgia, como nos bestiários, de combinar observações empíricas com propósitos morais e religiosos, e tudo isto no marco de uma profusa e abundante "imagería". (NAUGHTON, 2005, p. 18, tradução nossa)

Ainda que os bestiários, enquanto gênero, tenham perdido sua força com o final da Idade Média, eles continuaram a ecoar seu modelo híbrido ostensivamente, em especial através dos relatos fantásticos de viajantes europeus ao Novo Mundo, até o século XVIII, quando o racionalismo científico passou a dominar a relação do homem com o animal. A partir desse momento, contaminada por uma "visão objetiva e naturalista do reino animal" (MACIEL, 2008), a produção literária em torno do animal adquire novas feições, dessa vez predominantemente marcadas pela sistematização, pela observação e pela taxonomia.

É na América do Sul do século XX, entretanto, que dois escritores argentinos, cada um à sua maneira, abrem caminho para uma nova forma simbólica de articular a relação entre o homem e o animal através da composição de uma zooliteratura que irá dialogar tanto com o bestiário medieval quanto com a taxonomia cientificista de maneira bastante irônica, desviando-se da lógica fabulativa, moralizante e edificante de um e dos critérios rigorosos de classificação e compartimentação da outra, para tornar o bestiário uma figura literária híbrida e crítica e, assim, abrir novas possibilidades criativas para toda 
uma geração de artistas que os sucederão. Trata-se da proliferação animal que fazem surgir em Bestiário e Manual de zoología fantásticaque originará O livro dos seres imaginários -, respectivamente, Júlio Cortázar, em 1951, e Jorge Luis Borges (em livro escrito com a colaboração de Margarita Guerrero), em 1957.

Se ambos escritores partem de um mesmo universo imaginário, que podemos identificar com o bestiário, fazem-no por vias distintas: enquanto Borges aproveita-se da estética enciclopédica do saber de um bestiário tradicional, valendo-se da forma do verbete alfabeticamente ordenado para a composição de seu livro, Cortázar envereda pela fragmentação, apresentando uma diversidade de animais que surge vertiginosamente no cotidiano das personagens de seus primeiros contos reunidos em livro. Os bestiários aparecem aqui sob outras formas, subvertidos, pervertidos, relidos sob o olhar dos hispanoamericanos dos arrabaldes do Novo Mundo anteriormente conquistado pelo velho mundo europeu:

Em nossa época, o interesse pelos bestiários se renovou graças às expressões estéticas e literárias que o tomaram por objeto. Entre elas, a admirável Zoologia Fantástica de Borges, nosso maior escritor, e outras contribuições procedentes da música, da pintura e da escultura. E se no homem medieval a dimensão do "maravilhoso" tomasse parte do cotidiano, em nosso tempo o interrompe, o subverte, para abrir assim um espaço misterioso e recôndito, e talvez nele resida o interesse renovado por aquelas descrições fantásticas. (NAUGHTON, 2005, p. 22, tradução nossa)

Julio Cortázar, em Bestiario, já inicia sua subversão do bestiário enquanto gênero literário ao abrir o horizonte literário para seu uso como título de maneira inusitada, uma vez que seu livro é a reunião de narrativas onde não existe um princípio de catalogação direto. Na narrativa homônima do livro, Cortázar solta um tigre dentro da casa de uma pequena família de província, de modo que a família sempre precisa ocupar um cômodo onde o animal não esteja. Se essa "fuga" da animalidade mostra-se inevitável durante todo o volume - em "Carta a una señora de Paris", por exemplo, encontramos um personagem- 
hóspede que vomita coelhos -, na narrativa "Bestiario" encontram-se, por outro lado, pequenas maneiras de catalogação exercitadas pelas crianças-personagem do conto: "Folha número 74: verde, forma de coração, com pintinhas marrons" (CORTÁZAR, 2006, p. 147, tradução nossa). Cortázar inclui neste conto a catalogação na própria narrativa, e pelas mãos das crianças: depois do herbário, as crianças catalogam formigas (um formigário) e ainda abrangiam na pequena coleção insetos, caracóis (divididos por tamanhos e cores) e flores. Enquanto isso, a família continuava ameaçada pela presença do animal selvagem dentro da casa, seguindo sua rotina e evitando os cômodos onde o tigre poderia estar. Chama a atenção no conto, assim, ao lado da fuga da animalidade de que falamos anteriormente, ainda, a maneira de esta apresentar-se sempre como uma ameaça, uma presença a rondar os humanos que dela necessitam se esgueirar, uma vez que a sabem sempre por perto.

Mas, por que o tigre? A pergunta, longe de ser respondida, pode encontrar apenas uma reverberação em Manual de zoología fantástica e em $O$ livro dos seres imaginários, no qual se afirma que "para os anameses, tigres ou gênios personificados por tigres regem os rumos do espaço" (BORGES e GUERRERO, 2007, p. 202). O tigre, figura deslocada na fauna latino-americana, reaparece com destaque na zoologia de Borges, ainda mesmo na introdução de Manual de zoologia fantástica (BORGES e GUERRERO, 2001). Assim, pelo tigre e pelo bestiário, ambos os escritores introduziram na América Latina algo mais que um simples termo deslocado de seu uso, e sem proselitismo inauguraram formalmente a consciência de uma animalidade deste Novo Mundo frente aos mundos europeus, como encontramos um exemplo clássico no prólogo de Michel Foucault ao seu livro As palavras $e$ as coisas (2002), no qual ele confessa o riso perturbador que the surgiu diante da fauna de "uma certa enciclopédia chinesa" apresentada pela literatura de Jorge Luis Borges.

Conforme afirma Maciel, com esse movimento de diálogo com e de recriação a partir da tradição, Cortázar e Borges "revêem criticamente a 
tradição zooliterária anterior e convertem-se, simultaneamente, em uma coleção de textos precursores para os demais bestiários surgidos no contexto latino-americano do século XX" (MACIEL, 2008, p. 23), dos quais destacaremos alguns autores brasileiros.

No caso do poeta paulistano Claudio Daniel, partimos de um zoológico em miniatura intitulado "Figuras metálicas em expansão", contido no livro Figuras metálicas, de 2005, antologia que reuniu a obra do autor até a data da publicação. Dentre essas figuras que se expandem está aquele mundo animal que normalmente incomoda, que se destina ao extermínio, que o homem costuma desejar invisivel: formigas, traças, pulgas, baratas, piolhos. Um bestiário do mínimo, do que há de menos fantástico e mais indesejável no mundo animal.

Esse mínimo bestiário de parasitas que sobrevivem ao homem vive às custas delas: bebe de seu sangue, constitui-se de sua poética. Não é possivel ler a expansão dessas figuras metálicas e dessa miuçalha em verbetes sem articulá-las aos verbetes imaginários de Borges e aos vertiginosos fragmentos animais que se infiltram no bestiário do cotidiano de Cortázar, que por sua vez remetem ao simbolismo animal dos bestiários medievais e ao rigor taxonômico da ciência. Essa articulação, entretanto, faz-se pela via da invenção, da subversão e da inversão de valores, de caminhos, de propostas de leitura... Em lugar de finalidades moralizantes e educativas, a pura descrição insólita, a criação de imagens fantásticas, a ironia de uma "Formiga" ou de uma "Traça”:

Pequeno dragão/doméstico. // Cabeça grávida / de hibisco .// Rústico abdome- / cogumelo. // Escava o incerto /dos dias, // para a trilha / vertical // de farelo, fúria / e folhas. // Carrega seus mortos / nas costas, // com precisa / geometria // de fábrica / fúnebre. (DANIEL, 2005, p. 47)

(Entre fólios de ciência antiga e espectros de monjas nuas desencarnadas.) // (Olhos opiados afundam em partituras da Outra Margem.) // (Ruge um leão hipnótico.) // (Letras sangradas na pele de carneiro. Figuras metálicas em expansão.) // (Palavras criam realidades.) // (Traças cavam sendas no papel.) // (Toda leitura é uma cicatriz.). (DANIEL, p. 49) 
Com esse mínimo bestiário do indesejável dialoga também o poeta mineiro Ronald Polito, que cria em Terminal, de 2006, um "Minizoo" que remete, ainda, ao "Setor Microzoo" do Poliedro publicado por Murilo Mendes em 1972. O zoológico retoma do bestiário a noção da classificação e da organização dos animais num espaço, ainda que se trate agora de um espaço mais físico que textual (e ainda que os zoos a que nos referimos sejam poéticos...). Nesse zoológico em miniatura, Polito coloca em convivência não mais seres imaginários, nem animais parasitas, mas espécimes de uma fauna prosaica que por vezes são caracterizados humanamente, como um texugo autodidata ou um gnu acidental.

No espaço literário, Polito minimiza o espaço do animal encarcerado, estabelece os limites de sua jaula, descreve-o não mais científica ou pedagogicamente apenas; sua poesia incorpora o ecológico, a relação com o homem na contemporaneidade e todo o percurso crítico que a possibilitou. O espaço que resta ao texugo é o espaço do confinamento e do saber que decorre do lugar ocupado pelo homem, do olhar do outro sobre ele, mas aqui apresentado não mais pela via moral ou da edificação:

Refocinhando bem / o teu metro / quadrado / de vida, / você só vai encontrar / pedras inteiras e / aos pedaços, / palha para aparar /as pontas dos ossos, /além da reconhecida / voz diminuta do / caroço do crânio dizendo / palavras como: atenção, / esconda-se, ataque. // Mas, entre elas, a mais repetida será: / Não. /Assim ou numa frase constante da / breve linguagem: / isso não é para você. (POLITO, 2006, p. 45)

É também com um jardim zoológico que o paranaense Wilson Bueno, em 1999, faz mais uma incursão pelo universo zooliterário, que marca diversas de suas obras, limítrofes entre poesia e prosa. Essa mescla de gêneros não é a única forma através da qual Bueno se remete ao hibridismo dos bestiários medievais, sendo ele um dos escritores brasileiros que mais pervertem sua lógica fabulativa, incorporando à 
mesma elementos característicos dos relatos dos viajantes europeus e da cultura hispano-americana.

Seu zoológico, entretanto, vai estabelecer um marcante diálogo com O livro dos seres imaginários de Borges, sendo possivel até mesmo que o pensemos como uma resposta ao pedido do escritor argentino no prefácio do referido livro: "Convidamos o eventual leitor da Colômbia ou do Paraguai a enviar-nos os nomes, a fidedigna descrição e os hábitos mais conspícuos dos monstros locais" (BORGES e GUERRERO, 2007, p. 9). Com marcante caráter fantástico, o bestiário de Bueno

(...) é um compósito de elementos mitológicos, lendas indígenas, referências culturais brasileiras e hispano-americanas. Híbridos, fronteiriços, os bichos de Bueno são marcados pelos cruzamentos transnacionais advindos do contato entre os países do continente sul-americano. Além disso, são dotados de uma espécie de saber poético sobre a vida humana e sobre o próprio território que habitam, amalgamando características animais, humanas e divinas. (MACIEL, 2008, p. 34)

É nesse zoo, também organizado em verbetes, que Bueno rasura os limites entre real e imaginário, inserindo num mesmo "topos" institucionalizado do saber - o zoo - o fantástico do animal de Borges, o fragmentário do animal que surge em Cortázar e o caráter híbrido dos bestiários medievais. Nessa reunião de seres como ivitus, êulikes, nácares, agoalumens, catoblepas, zembras, lazúlis e limosos, quem aparece representado e repensado é o próprio homem, conforme aponta Maria Esther Maciel em Zoopoéticas contemporâneas (2007, p. 198): "Falar sobre um animal ou assumir sua persona não deixa de ser também um gesto de espelhamento, de identificação com ele. Em outras palavras, o exercício de animalidade que nos habita".

É desse zoológico situado na América Latina que surgem seres como os irús, entrecruzados com tradições outras, como as dos índios Guarani, que por essa via aparecem também no livro de Bueno:

Os irús, outros dos duendes do Chaco paraguaio, são incrivelmente engraçados - pequeninos e quase todos meio corcundas, andam aos magotes, abraçados uns nos outros como 
se não houvesse outra maneira de viver. Por isso, irú que dizer abraço, em guarani, derivando daí, segundo alguns etimologistas, a palavra, e não o contrário.

Descalços nos mínimos pés didáctilos - só o dedão e o minguinho, os irús começam a cantar mal dê o céu a sua aguada aurora, as pequenas mãos dadas; não raro, dizem os índios, dançam a churuchuchú, uma dança que joga as duas pernas para o alto e se cai de bunda no chão. (BUENO, 1999, p.81)

Nota-se, assim, que a relação dos seres desconhecidos com etimologias e costumes da América Latina não se limita apenas a apresentar e explicar o ser fantástico em si, e sim sua presença em nossos costumes, sua relação frente ao homem, nossa relação frente ao animal. O hibridismo do bestiário medieval chega, nessa literatura contemporânea, ao questionamento dos próprios limites e fronteiras rígidas que ao longo dos tempos se estabeleceu entre nós, humanos, e eles, os animais, como classificações absolutamente distintas.

É este hibridismo que destacamos ao finalizar nosso pensamento sobre alguns bestiários da literatura brasileira contemporânea com a obra de Nuno Ramos, artista visual e também escritor de São Paulo, do qual abordaremos o livro Cujo, publicado em 1993. Com textos de dificil classificação, a obra de Ramos caracteriza-se justamente pela multiplicidade de possibilidades, pela potencialidade de sentidos, pela transformação constante. Em Cujo encontramos aproximações plásticas a bestiários, além de um hibridismo textual com materialidade própria. Augusto Massi, na orelha do livro, assim o caracteriza:

Entre mórbido e onírico, fértil e escatológico, desfila um verdadeiro bestiário: baleia morta, polvo sem braços, a duração de um elefante, pele da cobra, gralha clara. Toda esta zoomorfia parece se render à lógica de um camaleão que "por exacerbação de seu conceito, tivesse uma única aparência". O camaleão está para a segunda voz assim como o espelho para a primeira, representa uma superficie capaz de abarcar todas as formas. Até quando se manifesta o desejo de arrancar a pele das coisas para ver o que há debaixo, existe uma constatação melancólica de que dá sempre no mesmo: "por trás de cada pele, portanto, encontrei apenas formas degradadas da pele superficial". A consciência esfola a pele das coisas. (MASSI, 1993) 
É esta aparência que Nuno Ramos explora. O artista, que parece "inventar uma pele para tudo" (RAMOS, 1993, p. 19), nos transporta para a superficie, apenas. E o que seria uma superficie de animal? Um animal sem o animal por dentro? É com a pele de um coelho que vamos ter o contato com esta superficie no seguinte fragmento:

A pele do coelho sem o coelho dentro: seus pelos penetram o couro por pequenos poros rosados. Há diferentes cores em cada pêlo, mas não muitas: semitons entre o amarelo e o castanho escuro e alguns albinos, também. É assim sem o coelho dentro. (RAMOS, p. 29)

Não há mais aqui a explicação, a moral, nem mesmo a distinção. Tudo se apresenta apenas em termos de superfície, e mesmo a troca da pele, a metamorfose, redunda sempre no mesmo. Não há o outro. E a superficie, a pele, em Nuno Ramos não é apenas do animal. O híbrido aqui é geral, não se distingue mais o homem, o animal, o objeto; tudo é o mesmo sob uma pele que se desdobra em outra:

Comecei a arrancar a pele das coisas. Queria ver o que havia debaixo. Ergui a superficie do assoalho, que saiu inteira, sem quebrar. Tive de descascar a pele dos tijolos aos poucos, com paciência. A pele do cimento era a mais fina de todas e a dos azulejos refletia como um espelho. Debaixo destas peles parecia haver outra pele, idêntica porém enrugada. Retirei mais esta camada e o enrugado da superficie aumentou. Fui retirando camadas sucessivas, cada vez mais onduladas e acidentadas. (...) A pele dos tijolos foi simplesmente virando pó: se no início era ainda possível descascá-la, havia perdido agora toda consistência e se desintegrava ao primeiro toque. Não era mais uma pele, nem uma superficie: transformara-se num material arenoso qualquer. Podia ser pó de tijolo, cal, areia ou, quem sabe, os restos de um defunto. Por trás de cada pele, portanto, encontrei apenas formas degradadas da pele superficial. Ainda que os dados não sejam suficientes, devo concluir que esta primeira camada não recobre um interior diferenciado, mas é a expressão mais estável deste interior, que a repete monotonamente. (RAMOS,p. 30-31)

A superficie explorada por Nuno Ramos também é algo que vai transformando sua própria matéria. Nos fragmentos de Cujo, o que se inicia como pele destina-se à aniquilação: "A pele do conteúdo cai. 
Depois de muitas peles, o próprio conteúdo cai. Depois o caído cai. Até a aniquilação" (RAMOS, p. 59).

Percorrendo esse breve catálogo de escritores brasileiros que, já em finais do século XX, optam por embrenhar-se no universo zooliterário, estabelecendo um diálogo transversal e plural com obras fundamentais como as de Julio Cortázar e Jorge Luis Borges, percebemos como nesse exercício - por vezes radical - de transformar o animal num mesmo, de negar a rigidez das fronteiras que os separam do homem, o escritor cria universos poéticos em que se desdobra como "outridade" a reflexão acerca da escrita do animal.

Retomamos, assim, a reflexão de Derrida sobre o emprego singular de animal que costuma ser feito com o intuito de abarcar um corpus de seres de natureza tão distinta como os que desfilaram ao longo deste breve artigo:

Neste conceito que serve para qualquer coisa, no vasto campo do animal, no singular genérico, no estrito fechamento deste artigo definido ("O animal" e "não animais") seriam encerrados, como em uma floresta virgem, um parque zoológico, um território de caça ou de pesca, um viveiro ou um abatedouro, um espaço de domesticação, todos os viventes que o homem não reconheceria como seus semelhantes, seus próximos ou irmãos. E isso apesar dos espaços infinitos que separam o lagarto do leão, o protozoário do golfinho, o tubarão do carneiro, o papagaio do chipanzé, o camelo da águia, o esquilo do tigre ou o elefante do gato, as formigas do bicho-da-seda ou o ouriço da equidna. (DERRIDA, 2002, p. 64-65)

Por este caminho Jacques Derrida seguiu em seu último seminário, intitulado La bête et le souverain (2001-2002), no qual o filósofo nos diz que a questão do animal é uma de suas preocupações permanentes. Sua preocupação se inicia com os artigos do título, la e le, gêneros de onde traduziriamos o animal por besta: $a$ besta e $o$ soberano, linhas de força que montam uma "cena" imposta pela consciência do título, uma intriga que desdobra a situação anterior de 
"o" animal que se instaura na ordem da aliança e da hostilidade (DERRIDA, 2008, p. 20). ${ }^{3}$

Assim, com seus exercícios zooliterários, iluminados pelos bestiários de Cortázar e Borges, Claudio Daniel, Ronald Polito, Wilson Bueno e Nuno Ramos parecem atuar justamente num campo de forças contrário, apresentando a impossibilidade de uma generalização, fazendo da mistura e da justaposição o espaço da convivência e do surgimento do diverso, da potência radical, mas com singularidade, pois dessa diferença instaurada pela literatura tudo pode surgir: "A troca constante entre as qualidades das peles devolveria ao mundo sua potencialidade original: a de tudo tornar-se a aparência de tudo, sem privilegiar nenhum momento específico." (RAMOS,p. 67).

É com essa "cena" que a literatura contemporânea brasileira se vale de uma singularidade, ao mesmo tempo em que situa um engano, a olhares generalizantes que conformam a literatura sempre na condição do mesmo, como se ela estivesse sem saída para ela própria. Aparentemente, apenas: pois, se ela se situa na condição do mesmo, é com uma troca de peles, uma metamorfose radical - para conjugarmos, assim, o pensamento de Jacques Derrida com o de Nuno Ramos e procurarmos ler uma pequena parcela dessa produção ainda em curso, a qual é o nosso risco.

Assim, essa literatura fornece uma outra pele para o sentido, lembrando que por mais celebrada que seja a figura do homem como animal superior, racional, "soberano", capaz de domar a natureza e se sobrepor aos demais animais, estes sim agrupados num outro singular genérico, "a besta", a literatura nos mostra um contrário, o equivalente ao que disse Gilles Deleuze em A literatura e a vida: "A vergonha de ser um homem: haverá razão melhor para escrever?" (DELEUZE, 1997, p. $11)$.

\section{Referências bibliográficas}

3 Pretendemos aprofundar essa discussão em outro artigo, uma vez que a mesma extrapolaria os limites e objetivos aqui propostos. 
BORGES, Jorge Luis e GUERRERO, Margarita. Manual de zoología fantástica. México: Fondo de Cultura Econômica, 2001.

BORGES, Jorge Luis e GUERRERO, Margarita. O livro dos seres imaginários. São Paulo: Companhia das Letras, 2007.

BUENO, Wilson. Jardim zoológico. São Paulo: Iluminuras, 1999.

CORTÁZAR, Julio. Bestiario. Buenos Aires: Suma de Letras, 2006.

DANIEL, Claudio. Figuras metálicas: travessia poética (1983-2003). São Paulo: Perspectiva, 2005.

DELEUZE, Gilles. "A literatura e a vida." In: DELEUZE, Gilles. Critica e Clinica. São Paulo: Editora 34, 1997.

DERRIDA, Jacques. O animal que logo sou. São Paulo: Editora Unesp, 2002.

DERRIDA, Jacques. Séminaire La bête et le souverain. Paris: Galilée, 2008. Vol. 1 (2001-2002).

FOUCAULT, Michel. As palauras e as coisas: uma arqueologia das ciências humanas. São Paulo: Martins Fontes, 2002.

MACIEL, Maria Esther. "Zoopoéticas contemporâneas" In: Remate de Males, Campinas, 27.2, jul/dez. 2007, p. 197-206.

MACIEL, Maria Esther. O animal escrito: um olhar sobre a zooliteratura contemporânea. São Paulo: Lumme, 2008.

MENDES, Murilo. Setor Microzoo. In: MENDES, Murilo. Poliedro. Poesia e Prosa Completa. Rio de Janeiro: Nova Aguilar, 1995.

NAUGHTON, Virginia. Bestiario medieval. Buenos Aires: Quadrata, 2005.

POLITO, Ronald. Terminal. Rio de Janeiro: 7 letras, 2006.

RAMOS, Nuno. Cujo. São Paulo: Ed. 34, 1993.

VARANDAS, Angélica. "A Idade Média e o bestiário." Medievalista Online, ano 2, n. 2, 2006. p. 1-53. Disponivel em: www2.fcsh.unl.pt/iem/medievalista/MEDIEVALISTA2/medievalistabestiario.htm. Último acesso em 22 jul. 2009. 